\title{
Is there any relationship between low PAPP-A levels and measures of umbilical vein and placental thickness during first trimester of pregnancy?
}

\author{
Gulsum Uysal, ${ }^{1}$ Sadan Tutus, ${ }^{2}$ Fulya Cagli, ${ }^{3}$ Cevdet Adiguzel ${ }^{1}$ \\ ${ }^{1}$ Department of Obstetrics and Gynecology, Adana Numune Training and Research Hospital, Adana, Turkey \\ 2Department of Radiology, Kayseri Training and Research Hospital, Kayseri, Turkey \\ ${ }^{3}$ Department of Obstetrics and Gynecology, Kayseri Training and Research Hospital, Kayseri, Turkey
}

\begin{abstract}
OBJECTIVE: Low pregnancy-associated plasma protein A (PAPP-A) level is associated with adverse perinatal outcomes. The purpose of this study was to evaluate relationship between umbilical cord diameter (UCD), umbilical vein and artery diameters (UVD, UAD), placental thickness, and PAPP-A level at gestational age of between 11 and 14 weeks.

METHODS: UCD, UVD, UAD, and placental thickness of 246 women were assessed during ultrasound examination at between 11 and 14 weeks of gestation, as well as measurement of nuchal translucency (NT) and crownrump length (CRL). Patients were divided into 2 groups according to PAPP-A percentile. Group 1 comprised 23 patients who had low PAPP-A ( $<0.44$ multiple of medians [MoM], $<10^{\text {th }}$ percentile) and Group 2 was made up of 223 patients with PAPP-A of $>0.44 \mathrm{MoM},>10^{\text {th }}$ percentile. Calipers used for measurement were placed inner edge to inner edge of echogenic boundaries of the vessel. Largest sections of all vessels (UV and both arteries) were evaluated. Thickest part of the placenta was used for placental thickness measurement.
\end{abstract}

RESULTS: Narrow UCD $(<4.5 \pm 0.6 \mathrm{~mm})$ was associated with low PAPP-A level $(\mathrm{p}=0.02)$. There was no significant difference in UVD, UAD, or placental thickness between groups. There was no significant difference in gestational age, CRL, or NT between groups. Fetal birth weight was significantly lower in Group $1(p=0.03)$.

CONCLUSION: Closer attention to women with low-risk, healthy pregnancies and low PAPP-A level in first trimester screening results is recommended. They should be routinely screened for background medical risk factors and umbilical cord morphology in first trimester scan.

Keywords: First trimester; placental thickness; pregnancy-associated plasma protein A; umbilical cord; umbilical vein.

Received: January 04, 2017 Accepted: March 20, 2017 Online: May 10, 2017

Correspondence: Dr. Gulsum UYSAL. Adana Numune Egitim ve Arastirma Hastanesi, 00170 Adana, Turkey.

Tel: +90 322 - 3550000 e-mail: gulsumaykut@yahoo.com

(c) Copyright 2017 by Istanbul Northern Anatolian Association of Public Hospitals-Available online at www.kuzeyklinikleri.com 
$\mathrm{T}$ he umbilical cord is a bridge organ between mother and fetus, and can be easily measured in the first trimester with improvements made to ultrasound probes used in imaging. Although we dispose of the umbilical cord at birth, it plays a unique role in fetal-placental unit.

There are 2 arteries and single vein in the Warton's jelly of standard umbilical cord [1]. Morphology of umbilical cord structure alters in presence of various pathological conditions, such as hypertensive disorders [2], gestational diabetes [3], fetal distress [4], and growth restriction [5]. Moreover, umbilical cords with single artery [6], lean cords [4], and short cords [7] have been reported in cases with chromosomal defects and genetic syndromes. However, sonographic size of the umbilical cord in first trimester during routine prenatal sonographic scan receives little attention.

Pregnancy-associated plasma protein A (PAPP. A), which is encoded by the PAPPA gene in humans, is a protein. Low plasma level of PAPP-A has been recommended as biochemical marker for pregnancy with aneuploid fetus [8]. Moreover, low level has been observed in situations such as intrauterine growth restriction (IUGR) [9], preeclampsia [10], placental abruption, premature birth, fetus that is small for gestational age (SGA), and fetal death [11].

The aim of this study was to evaluate relationship between umbilical cord thickness, umbilical vein and artery diameter, placental thickness, and PAPP-A level at gestational age of between 11 and 14 weeks.

\section{MATERIALS AND METHODS}

This prospective study was conducted at Kayseri Education and Research Hospital, a tertiary teaching hospital in Kayseri, Turkey. Ethics approval for the study was obtained from Erciyes University Hospital (protocol number: 2014/290).

Total of 246 consecutive women with singleton pregnancy who presented spontaneously for combined first trimester screening between April and December 2014 were included in the study. $\mathrm{Pa}$ tients with multiple pregnancy or pregnancy with

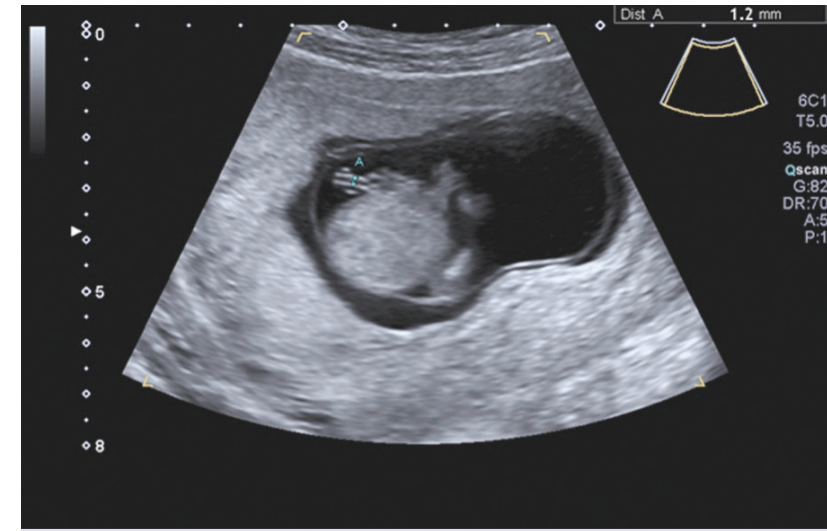

FIGURE 1. Umbilical vein diameter was measured at the widest distance between the opposing walls of the vein.

structural fetal anomaly were excluded. The present study was conducted according to the recommendations of the Declaration of Helsinki on Biomedical Research Involving Human Subjects. Written informed consent was obtained from all patients.

Umbilical cord diameter (UCD), umbilical vein and artery diameters (UVD, UAD), and placental thickness were assessed during detailed ultrasound examination at between 11 and 14 weeks of gestation, as well as nuchal translucency (NT) and crown-rump length (CRL) measurements. All ultrasound examinations were carried out with Xario device (Toshiba Medical Systems Corp., Otawarashi, Tochigi, Japan) equipped with 2.8-7 $\mathrm{MHz}$ transducer. Scans were performed transabdominally by a single radiologist (S.T.).

Maternal age, gravida, parity, and gestational age were recorded. Gestational age was calculated from first day of last period and confirmed ultrasonographically at first trimester scan. Data of gestational age and fetal birth weight after delivery were also recorded.

During ultrasound examination, a free loop of umbilical cord was identified and magnified to obtain an appropriate image for measurement. UCD was measured from outer edge to outer edge. Diameter of UVD was measured at widest distance between opposing walls of the vein (Figure 1).

Calipers for measurement were placed on echogenic boundary of the vessel from inner edge to in- 


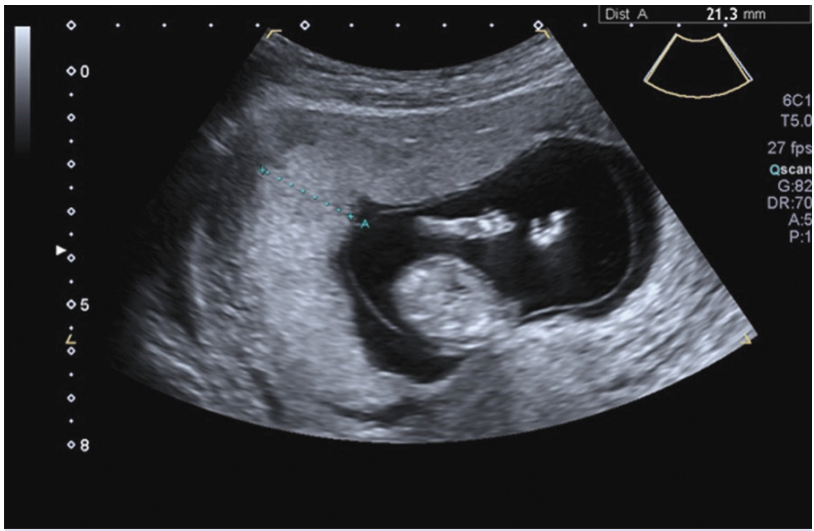

FIGURE 2. Placental thickness measurement was recorded at the thickest part of the placenta.

ner edge. Largest sections of all vessels (UV and both arteries) were evaluated. Average of both vessels was calculated for UAD. Thickest part of the placenta was used for placental thickness measurement, as shown in Figure 2.

Fetal CRL and NT were measured in all women according to recommendations of the Fetal Medicine Foundation [12].

PAPP-A measurement was conducted using UniCel Dxl 800 Access immunoassay system analyzer (Beckman Coulter, Inc, Brea, CA, USA), which is used for routine first trimester prenatal screening program. PAPP-A values were converted to gestation-specific multiple of medians (MoM), using Prisca software program (Siemens Healthcare Diagnostics, Erlangen, Germany).

Patients were divided into 2 groups according to PAPP-A value. Those below $10^{\text {th }}$ percentile in MoM of PAPP-A were classified as Group 1, and those above $10^{\text {th }}$ percentile were classified as Group 2 .

All analyses were performed using PASW Statistics for Windows, Version 18.0 (SPSS, Inc, Chicago, IL, USA). Quantitative variables were expressed as mean value $\pm \mathrm{SD}$ for parametric variables and median and minimum-maximum levels for nonparametric variables. Continuous variables were analyzed for normal distribution using Kolmogorov-Smirnov test. A 2-tailed $\mathrm{p}<0.05$ was considered significant. Differences in continuous variables between 2 groups were determined by
TABLE 1. Basal characteristics of patient groups

\begin{tabular}{lccc} 
& $\begin{array}{c}\text { Group 1 } \\
\text { PAPP-A }<\% 10 \\
(<0.44 \text { MoM) })\end{array}$ & $\begin{array}{c}\text { GAPP-A }>\% 10 \\
(>0.44 \text { MoM })\end{array}$ & $\begin{array}{c}\mathrm{p} \\
(<0.05)\end{array}$ \\
& $29.0 \pm 6.2$ & $26.4 \pm 5.7$ & 0.04 \\
\hline $\begin{array}{l}\text { Age (years) } \\
\text { Gravida (n) }\end{array}$ & & & \\
Median (min-max) & $3(1-6)$ & $2(1-8)$ & 0.001 \\
$\begin{array}{l}\text { Parity (n) (mean) } \\
\text { Gestational age }\end{array}$ & $2(0-4)$ & $1(0-4)$ & 0.002 \\
(weeks) & $12.4 \pm 0.5$ & $12.3 \pm 0.5$ & 0.4 \\
$\begin{array}{l}\text { CRL (mm) } \\
\text { NT (mm) }\end{array}$ & $66.6 \pm 8.0$ & $65.1 \pm 7.5$ & 0.38 \\
$\begin{array}{l}\text { Fetal birth weight } \\
\text { (gr) }\end{array}$ & $2945 \pm 522$ & $3237 \pm 546$ & 0.01 \\
Gestational age & $37.2 \pm 3.0$ & $38.2 \pm 3.0$ & 0.1 \\
at delivery (week) & & & \\
\hline
\end{tabular}

CRL: Fetal crown-rump length; MoM: Multiple of medians; NT: Nuchal translucency; PAPP-A: Pregnancy-associated plasma protein-A.

Student's t-test or Mann-Whitney U test. Logistic regression analysis using the enter method was performed for multivariate analysis of independent predictors. Significant parameters $(p<0.05)$ were entered into multivariate analysis.

\section{RESULTS}

Total of 246 umbilical cords of healthy pregnancies were evaluated in the study. Scans of umbilical cord vessels and placental thickness were successfully examined in all cases.

There were 23 patients in Group 1, defined as below the $10^{\text {th }}$ percentile in MoM of PAPP-A $(<0.44 \mathrm{MoM})$ and 223 patients in Group 2, above the $10^{\text {th }}$ percentile in MoM of PAPP-A $(>0.44$ MoM). Characteristics of the patients by group and measurement of CRL, NT, and fetal weight are presented in Table 1 .

Maternal age, gravida, and parity were significantly higher in Group 1 (PAPP-A <0.44MoM) compared with Group 2. Mean maternal age was $29 \pm 6.2$ in Group 1 and 26 \pm 5.7 in Group 2. There was no significant difference in gestational age, gestational 
TABLE 2. Relationship between groups and umbilical vessel diameter and placental thickness

\begin{tabular}{lccc} 
& $\begin{array}{c}\text { Group 1 } \\
\text { PAPP-A }<\% 10 \\
(<0.44 \text { MoM })\end{array}$ & $\begin{array}{c}\text { Group 2 } \\
\text { PAPP-A }>\text { \%10 } \\
(>0.44 \text { MoM })\end{array}$ & $\begin{array}{c}\mathrm{p} \\
(<0.05)\end{array}$ \\
\hline UCD (mm) & $4.5 \pm 0.6$ & $4.8 \pm 0.5$ & 0.02 \\
UVD (mm) & $1.6 \pm 0.2$ & $1.6 \pm 0.2$ & 0.9 \\
UAD (mm) & $1.2 \pm 0.2$ & $1.2 \pm 0.1$ & 0.5 \\
Placental thickness & $16.8 \pm 2.9$ & $16.9 \pm 3.3$ & 0.8 \\
(mm) & & & \\
\hline
\end{tabular}

MoM: Multiple of medians; PAPP-A: Pregnancy associated plasma proteinA; UAD: Umbilical artery diameter; UCD: Umbilical cord diameter; UVD: Umbilical vein diameter.

TABLE 3. Multivariate analysis

\begin{tabular}{lccc} 
& $\begin{array}{c}\text { Multivariate } \\
\text { odds ratio }\end{array}$ & $95 \% \mathrm{CI}$ & $\mathrm{p}$ \\
\hline Age & 0.959 & $0.875-1.052$ & 0.38 \\
Gravida & 0.820 & $0.466-1.442$ & 0.49 \\
Parity & 0.691 & $0.292-1.637$ & 0.40 \\
Fetal birth weight & 1.001 & $1.000-1.002$ & 0.031 \\
UCD & 2.638 & $1.140-6.103$ & 0.023 \\
\hline
\end{tabular}

CI: Confidence interval; UCD: Umbilical cord diameter.

age at delivery, CRL, or NT between groups. Fetal birth weight was significantly lower in Group 1.

Values for diameter of umbilical cords, vessels, and placental thickness are provided in Table 2. There was no difference in UVD, UAD, or placental thickness between groups. UCD was significantly greater in Group 2.

Significant parameters of univariate analysis $(p<0.05)$ were entered into multivariate analysis (age, gravida, parity, fetal birth weight, UCD). UCD was found to be an independent predictor of low PAPP-A level (odds ratio [OR], 2.638; 95\% confidence interval [CI], 1.140-6.103; $\mathrm{p}=0.023)$, together with fetal birth weight (OR, 1.001; 95\% CI, 1.000-1.002; $\mathrm{p}=0.031$ ) (Table 3).

\section{DISCUSSION}

Major finding of our study was that there is relationship between diameter of umbilical cord and PAPP$\mathrm{A}$, one of the first trimester biochemical markers. Low PAPP-A level in first trimester appeared to be associated with narrow UCD $(<4.5 \pm 0.6 \mathrm{~mm})$. UCD or umbilical cord morphology evaluation is not routine scan during first trimester ultrasound. In a recent study it was reported that UCD in first trimester was related to growth of the embryo, and may be used as ultrasonographic measurement to detect risks to fetus, such as spontaneous abortion or preeclampsia [2]. Furthermore, Ghezzi et al. indicated that more than half of cases with fetal demise that occurred early in second trimester had thinner umbilical cord (diameter $<2 \mathrm{SD}$ ) compared with UCD scan in first trimester [2].

We know that low PAPP-A level is associated with poor perinatal outcomes, including fetus that is SGA, preterm delivery, hypertensive disorders of pregnancy, and stillbirth [13]. In a recent study, Wells et al. concluded that PAPP-A can be used as new biomarker for maternal diabetes [14]. They also reported that markedly decreased PAPP-A level was associated with severe gestational diabetes. Therefore, it may predict risk of gestational diabetes [14].

The questions is, what is the cause of low PAPPA level and adverse perinatal outcome? Abnormal placentation has been suspected in recent studies $[15,16]$. Actually, they suggested that women who had low PAPP-A level in first trimester with normal first trimester aneuploidy screening results should be screened routinely for risk factors related to abnormal placentation. Avsar et al. evaluated relationship between first trimester PAPP-A level and intrapartum fetal distress results. They revealed that PAPP-A level was lower $(<0.5 \mathrm{MoM})$ in cases with intrapartum fetal distress [17]. Additionally, in another study, patients who had cord insertion on the lower segment of the uterus had lower maternal serum PAPP-A level [18]. In our study, narrower UCD $(<4.5 \pm 0.6 \mathrm{~mm})$ was associated with low PAPP-A level (<0.44MoM) in aneuploidy screening results of first trimester. We have also reported 
that there was no relationship between low PAPPA level (<0.44MoM) and UVD, UAD, or placental thickness. This is the first study to evaluate association between UVD, UAD, placental thickness, and PAPP-A. We think that changing role of Wharton's jelly, which increases as gestation advances, may explain insignificant relationship between low PAPPA level and UVD, UAD, and placental thickness. Umbilical cord is part of fetal metabolism and it has been suggested that thickness of umbilical cord may be related to mechanism of fetal nutrition [19]. Both thick and thin umbilical cords might be dependent on quantity of Warton's jelly and/or changing size of umbilical cord vessels in cross-sectional area [20]. Further larger studies are needed to explain probable relationship between umbilical cord, morphology of Warton's jelly, and fetal outcome in early pregnancy.

In our study, low PAPP-A value in first trimester combined test in low-risk healthy pregnancy was associated with lower fetal birth weight at term. Studies in the literature report relationship between low PAPP-A level and SGA infant. It has been demonstrated that there was statistically significant relationship between PAPP-A level below fifth percentile or less than $0.4 \mathrm{MoM}$ and SGA or IUGR [9, 21]. Abnormal placentation may be behind low level of PAPP-A and adverse outcomes. Larger studies should be helpful to bring focus to pathogenesis. On the other hand, in another study, Saruhan et al. found that PAPP-A level below $10^{\text {th }}$ percentile was not significantly associated with SGA [22]. Current consensus on association between PAPP-A level below $10^{\text {th }}$ percentile and SGA remains mixed.

Our data indicated that as maternal age and gravida increase, frequency of low PAPP-A level $(<0.44 \mathrm{MoM})$ increases in low-risk, healthy pregnancies in first trimester scan. It might be explained by placental damage, which can be greater with advanced maternal age and complex obstetric history.

There are several limitations to our study. Our study protocol did not include longitudinal followup cord anatomy through gestation in second or third trimester. We did not have a high-risk, first trimester pregnancy group; therefore, we could not perform measurement of diameter of umbilical cord and vessels in high-risk group. Major limitation of our study was relatively small patient population. Studies involving larger number of participants should be conducted to verify and further advance our findings. Also, we could not include pregnancy outcome (e.g., diabetes, preeclamsia, or growth retardation) other than fetal birth weight.

In conclusion, our data revealed that UCD was independent predictor of low PAPP-A level. Although there is debate about cut-off of low PAPP-A level (under $10^{\text {th }}$ or $5^{\text {th }}$ percentile), it would seem to be worthwhile to pay attention to low PAPP-A level. We suggest closer attention be paid to performing umbilical cord measurements in first trimester scan. Larger prospective studies need to be performed to further investigation of UCD and cord vessel evaluations in first trimester of gestation. There are many questions that remain to be solved about potential role of umbilical cord morphology in fetal outcome.

\section{Conflict of Interest: None declared.}

Ethical approval: All procedures performed in studies involving human participants were in accordance with the ethical standards of the institutional and/or national research committee and with the 1964 Helsinki Declaration and its later amendments or comparable ethical standards.

Informed consent: Informed consent was obtained from all patients who were included in our study.

Financial Disclosure: The authors declared that this study has received no financial support.

Authorship contributions: Concept - G.U.; Design - G.U.; Supervision - C.A., F.U.; Materials - S.T.; Data collection and/ or processing - F.C., G.U.; Literature earch - S.T., F.C.; Writing - G.U.; Critical review - C.A.

\section{REFERENCES}

1. Wu MH, Chang FM, Shen MR, Yao BL, Chang $\mathrm{CH}, \mathrm{Yu} \mathrm{CH}$, et al. Prenatal sonographic diagnosis of single umbilical artery. J Clin Ultrasound 1997;25:425-30.

2. Ghezzi F, Raio L, Di Naro E, Franchi M, Brühwiler H, D’Addario $\mathrm{V}$, et al. First-trimester sonographic umbilical cord diameter and the growth of the human embryo. Ultrasound Obstet Gynecol 2001;18:348-51.

3. Weissman A, Jakobi P. Sonographic measurements of the umbilical cord in pregnancies complicated by gestational diabetes. J Ultrasound Med 1997;16:691-4.

4. Raio L, Ghezzi F, Di Naro E, Franchi M, Maymon E, Mueller MD, et al. Prenatal diagnosis of a lean umbilical cord: a simple 
marker for the fetus at risk of being small for gestational age at birth. Ultrasound Obstet Gynecol 1999;13:176-80.

5. Bruch JF, Sibony O, Benali K, Challier JC, Blot P, Nessmann C. Computerized microscope morphometry of umbilical vessels from pregnancies with intrauterine growth retardation and abnormal umbilical artery Doppler. Hum Pathol 1997;28:1139-45.

6. Persutte WH, Hobbins J. Single umbilical artery: a clinical enigma in modern prenatal diagnosis. Ultrasound Obstet Gynecol $1995 ; 6: 216-29$.

7. Gilbert-Barness E, Drut RM, Drut R, Grange DK, Opitz JM. Developmental abnormalities resulting in short umbilical cord. Birth Defects Orig Artic Ser 1993;29:113-40.

8. Chitayat D, Langlois S, Wilson RD; Genetics Committee of the Society of Obstetricians and Gynaecologists of Canada; Prenatal Diagnosis Committee of the Canadian College of Medical Geneticists. Prenatal screening for fetal aneuploidy in singleton pregnancies. J Obstet Gynaecol Can 2011;33:736-50.

9. Carbone JF, Tuuli MG, Bradshaw R, Liebsch J, Odibo AO. Efficiency of first-trimester growth restriction and low pregnancyassociated plasma protein-A in predicting small for gestational age at delivery. Prenat Diagn 2012;32:724-9.

10. Poon LC, Maiz N, Valencia C, Plasencia W, Nicolaides KH. First-trimester maternal serum pregnancy-associated plasma protein-A and pre-eclampsia. Ultrasound Obstet Gynecol 2009;33:23-33.

11. Marttala J, Peuhkurinen S, Laitinen P, Gissler M, Nieminen P, Ryynanen M. Low maternal PAPP-A is associated with smallfor-gestational age newborns and stillbirths. Acta Obstet Gynecol Scand 2010;89:1226-8.

12. Nicolaides KH. Nuchal translucency and other first-trimester sonographic markers of chromosomal abnormalities. Am J Obstet Gynecol 2004;191:45-67.

13. Balc1 S. Predictive values of maternal serum PAPP-A level, uterine artery Doppler velocimetry, and fetal biometric measurements for poor pregnancy and poor neonatal outcomes in pregnant women. J Turk Ger Gynecol Assoc 2016;17:143-9.

14. Wells G, Bleicher K, Han X, McShane M, Chan YF, Bartlett A, et al. Maternal Diabetes, Large-for-Gestational-Age Births, and First Trimester Pregnancy-Associated Plasma Protein-A. J Clin Endocrinol Metab 2015;100:2372-9.

15. Proctor LK, Toal M, Keating S, Chitayat D, Okun N, Windrim $\mathrm{RC}$, et al. Placental size and the prediction of severe early-onset intrauterine growth restriction in women with low pregnancyassociated plasma protein-A. Ultrasound Obstet Gynecol 2009;34:274-82.

16. Rizzo G, Silvestri E, Capponi A, Servadei F, Pietrolucci ME, Capece A, et al. Histomorphometric characteristics of first trimester chorionic villi in pregnancies with low serum pregnancyassociated plasma protein-A levels: relationship with placental three-dimensional power doppler ultrasonographic vascularization. J Matern Fetal Neonatal Med 2011;24:253-7.

17. Avşar AF, Seçen Eİ, Akçay GF, Keskin HL, Taş EE, Dalgacı AF. The relationship between first-trimester pregnancy-associated plasma protein-A levels and intrapartum fetal distress development. J Turk Ger Gynecol Assoc 2016;17:139-42.

18. Hasegawa J, Farina A, Simonazzi G, Bisulli M, Puccetti C, Pilu $\mathrm{G}$, et al. Umbilical cord insertion into the lower segment of the uterus at 11 to 13 weeks' gestation is associated with maternal serum PAPP-A. Prenat Diagn 2011;31:434-8.

19. Raio L, Ghezzi F, Di Naro E, Gomez R, Franchi M, Mazor M, et al. Sonographic measurement of the umbilical cord and fetal anthropometric parameters. Eur J Obstet Gynecol Reprod Biol 1999;83:131-5.

20. Ghezzi F, Raio L, Günter Duwe D, Cromi A, Karousou E, Dürig P. Sonographic umbilical vessel morphometry and perinatal outcome of fetuses with a lean umbilical cord. J Clin Ultrasound 2005;33:18-23.

21. Marttala J, Peuhkurinen S, Laitinen P, Gissler M, Nieminen P, Ryynanen M. Low maternal PAPP-A is associated with smallfor-gestational age newborns and stillbirths. Acta Obstet Gynecol Scand 2010;89:1226-8.

22. Saruhan Z, Ozekinci M, Simsek M, Mendilcioglu I. Association of first trimester low PAPP-A levels with adverse pregnancy outcomes. Clin Exp Obstet Gynecol 2012;39:225-8. 